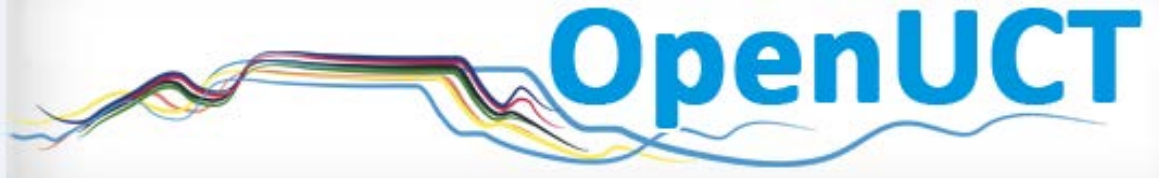

This is the post-print of Smith, L. C. 2009. An analysis of the impact of pedagogic interventions in first-year academic development and mainstream courses in microeconomics. South African Journal of Economics.77(1): 162178. DOI: 10.1111/j.1813-6982.2009.01195.x.

It is made available according to the terms of agreement between the author and the journal, and in accordance with UCT's open access policy available: http://www.openuct.uct.ac.za/sites/default/files/UCTOpenAccessPolicy.pdf, for the purposes of research, teaching and private study. 


\title{
AN ANALYSIS OF THE IMPACT OF \\ PEDAGOGIC INTERVENTIONS IN FIRST-YEAR \\ ACADEMIC DEVELOPMENT AND \\ MAINSTREAM COURSES IN \\ MICROECONOMICS
}

\author{
LEONARD C. SMITH*
}

\section{Abstract}

This paper analyses the impact of pedagogic interventions in first-year academic development and mainstream courses in microeconomics on students' performance in the final examination. The data for six cohorts, covering the years 1999 and 2001-2005 is pooled, and the Heckman two-part procedure is used to account for those students who started the course but did not write the final examination. The results suggest that the pedagogic interventions have a positive impact on the performance of academic development students relative to the mainstream cohort and on the performance of mainstream students.

JEL Classification: I21

Keywords: academic development, student performance, South Africa, economic education

\section{INTRODUCTION}

Academic development programmes and courses have been used extensively in South African higher education institutions over the last 25 years. These have taken a variety of forms, including parallel courses, bridging courses, extra tutorials, and additional courses in English and mathematics (Walker and Badsha, 1993, Volbrecht, 1999, Edwards, 2000, Smith, 2004, and Smith and Edwards, 2007).

The aim of these interventions is to enable students from academically and socially disadvantaged backgrounds to develop their literacy, quantitative and study skills, so that they are able to achieve success in a particular course, complete mainstream ${ }^{1}$ courses and ultimately achieve a higher education qualification. In addition they are also designed to facilitate students' understanding of the subject. However, despite the pervasiveness of these interventions it is fair to say that relatively little research has been carried out to test the efficacy of these interventions in improving the

\footnotetext{
* Centre for Higher Education Development at the University of Cape Town. Email: Leonard.Smith@uct.ac.za.

I would like to thank Lawrence Edwards, Corné van Walbeek, and two anonymous referees for helpful comments that improved this paper, and Fiona Gibbons for her patience in meeting my numerous requests for data. All errors are, of course, my responsibility.

1 "Mainstream" refers to those courses that make-up the standard three- and four-year degree programmes (Volbrecht, 1999).
} 
performance of students in mainstream and academic development courses (Edwards, 2000, Smith, 2004, and Smith and Edwards, 2007).

This lack of research is not unique to South Africa. There is an extensive literature on the use, and evaluation, of support (remediation) programmes in colleges in the USA (Ramirez, 1997, Weismann, Bulakowski and Jumisko, 1997, Boylan and Saxon, 1999, Brothen and Wambach, 2004, and Bettinger and Long, 2005). However, little research has been undertaken to test the efficacy of these programmes (O'Hear and MacDonald, 1995, MacDonald and O'Hear, 1996, and Boylan and Saxon, 1999). That said, the research that has been undertaken suggests that there are benefits to students who attend academic development or support courses (Boylan and Saxon, 1999, Smith, 2004, and Smith and Edwards, 2007).

This study builds on the work of Smith and Edwards (2007); they tested the efficacy of an academic development course in first-year microeconomics, at the University of Cape Town, relative to a control group drawn from the mainstream course. In their study the efficacy of the academic development course was measured in terms of success in the current, and in subsequent, courses in macroeconomics and microeconomics, using the usual control variables. The key findings were that students on the academic development course outperformed mainstream students by an average of 15 percentage points for the structured/essay questions in the first-year microeconomics examination, and by an average of 12 percentage points for the structured/essay questions in the second-year microeconomics examination. The latter result suggests that the skills acquired in first-year academic development courses in microeconomics persist into further years.

This study makes three advances to the literature in this area. Firstly, in contrast to the studies of Edwards (2000) and Smith and Edwards (2007) this study pools the data for different years. The matriculation examinations are standardised across provinces and very few changes have been made to the content of the first-year microeconomics course during the period, or to the content, structure and standard of the final examination paper. There are two advantages in using this approach; it makes it possible to evaluate the effectiveness of the pedagogic interventions in improving students' performance in the longer term, and a more robust set of results is generated than is previously the case.

In general, studies of the determinants of performance in economics courses tend to use relatively small samples. For example, a survey of 15 studies undertaken in the United States, and reported in the Journal of Economic Education over the period 20002007, showed sample sizes ranging from 57 to 1011 observations with a mean of 449 observations. ${ }^{2}$ For seven studies of commerce and economics students at South African universities, the sample sizes range from 26 to 813 observations, with a mean of 526 observations. ${ }^{3}$ For five studies focussing on academic development students undertaking business economics and economics at South African universities, the

\footnotetext{
2 Chizmar (2000), Ziegert (2000), Marburger (2001), Ashworth and Evans (2001), Sowell (2004), Bosshardt (2004), Arias and Walker (2004), Krohn and O'Connor (2005), Anstine and Skidmore (2005), McPherson (2006), Marburger (2006), Grove, Wasserman and Grodner (2006), Swope and Schmitt (2006), Stanca (2006), and Alston and Nowell (2007).

${ }^{3}$ Hesketh, Mbali and Mkhize (1994), Van Walbeek (2004), and Parker (2006).
} 
sample sizes range from 177 to 424 observations with a mean of 311 observations. ${ }^{4}$ The sample size for this study is 2408 observations as opposed to an overall mean of 443 observations for the studies cited above.

Secondly, the Heckman two-part procedure (Heckman, 1979) is used to account for the sample selection problem that arises, as not all the students who start the course write the final examination. ${ }^{5}$ Omitting these students from the estimations may bias the results. This also makes possible the generation of a more robust set of results than is previously the case. Thirdly, the effect of of pedagogic interventions on the performance of students undertaking the mainstream course is evaluated.

This paper has two aims. Firstly, to identify the extent to which the academic development course in first-year microeconomics (ECO1010H) is successful in improving students' performance relative to a control group drawn from the mainstream (ECO1010S). Using the same methodology as Smith and Edwards (2007), the effectiveness of the academic development course in microeconomics is tested using pooled data that includes the 1999, and 2001-2005 cohorts; the academic development and mainstream cohorts wrote the identical examination at the same sitting in each of the years This contrasts with the Smith and Edwards' (2007) study, which used data for the 2001 cohort only. Secondly, to determine the effectiveness of the pedagogic interventions of an academic development type in improving the performance of mainstream students relative to the performance of students completing the academic development course.

The structure of the paper is as follows. In Section 2 the academic development $(\mathrm{ECO} 1010 \mathrm{H})$ and mainstream (ECO1010S) courses in first-year microeconomics are described. ${ }^{6}$ In Section 3 the empirical methodology used in this paper is presented. Section 4 considers the data used and discusses the results, and Section 5 concludes the paper.

\section{ACADEMIC DEVELOPMENT AND MAINSTREAM COURSES IN FIRST-YEAR MICROECONOMICS}

The academic development (ECO1010H) and the mainstream (ECO1010S) courses in first-year microeconomics are described in Smith and Edwards's (2007) paper. In summary, the ECO1010H course includes short modules on quantitative techniques, graphical analysis, and introductory macroeconomics in addition to the core first-year microeconomics course, which mirrors that of the shorter single-semester mainstream courses in microeconomics (ECO1010F and ECO1010S). Tests are set to the same standard and, with the exception of 2000, ECO1010S and ECO1010H students wrote the identical final examination at the same sitting. Copies of previous test and examination papers were made available from short loan in the university's main library.

\footnotetext{
${ }^{4}$ Curtis and De Villiers (1992), De Villiers and Rwigema (1998), Edwards (2000), Smith (2004) and Smith and Edwards (2007).

5 The Heckman two-part procedure is described in some detail below. Parker (2007) gives a clear explanation of how to use this procedure in a similar context.

${ }^{6}$ The School of Economics offers two mainstream first-year one-semester microeconomics courses, ECO1010F (F refers to first semester) and ECO1010S (S refers to second semester). Students who fail ECO1010F can repeat the course in the second semester.
} 
The majority of the students registered for ECO1010S (80\%) are repeating the firstyear microeconomics course, having failed the first-semester course, ECO1010F.

Therefore, they spend the same amount of time studying the subject and the allocation of teaching resources to the two courses is comparable.

There are several important differences between the two courses with respect to the structure, content and teaching approach, which the interventions introduced in 2003 did not eliminate entirely. The ECO1010H course runs over two semesters as opposed to a single semester, five lectures are offered per week as opposed to four, and classes are small (80 to 120 students) relative to the size of mainstream lecture groups (150 to 400 students). Greater emphasis is placed on using the tutorial system as a vehicle to develop students' meta-learning skills. A weekly double-period language and communication tutorial, consisting of about 25 students, is used to improve students' essay-writing skills and their referencing and comprehension techniques. Students also take a weekly double-period economics tutorial, consisting of 15 students, in which students are required to complete and submit written answers to a set tutorial made up of multiple-choice, paragraph/structured/essay, true/false, fill-in, calculation and casestudy questions. The greater number and duration of the tutorials gave ECO1010H students the opportunity to refine their understanding of the subject, and to develop their skills in answering different types of questions. The grades received for these assignments contribute towards the students' final marks. Tutors for both tutorials are chosen on the basis of their subject knowledge and pedagogic ability, and of the degree of their commitment to enabling academic development students to make a success of their microeconomics course. The relatively few tutors receive advice and support from the course convener both in tutor meetings and at other times when necessary. The performance of the tutors is monitored by the course convener and students submit evaluations of their tutors during the course. The aim of this support and assessment is to encourage tutors to perform to the best of their ability.

The economics tutorials offered by the mainstream course pays less attention to the development of students' meta-learning skills. Each week, students attend a singleperiod tutorial during which various multiple-choice and structured/essay-type questions are discussed. Students are required to submit written work less frequently and their grades for these assignments do not count towards the students' final marks. Further, no language and communication tutorials are offered. Tutors receive less training and support compared to those leading ECO1010H tutorials.

The assessment of the students during the academic development course also differs from that of the mainstream course. Forms of assessment include the tutorials, three essays, four tests and the final examination. ${ }^{7}$ The tests include multiple-choice and structured/essay questions in the ratio of about 30 to 70 . In contrast, students in the mainstream economics courses are not required to submit essays and their tests consist solely of multiple-choice questions. ${ }^{8}$

\footnotetext{
7 The final mark is made up as follows: three essays at $5 \%$ each (15\%), three tests at $5 \%$ each $(15 \%)$, one test at $10 \%(10 \%), 20$ written economics tutorials $(5 \%)$ and the final examination $(55 \%)$.

8 The ECO1010F/S final mark is made up of the marks gained in two or three multiple-choice tests and the final examination. The tests count $45 \%$ of the final mark.
} 
In 2003 a number of changes designed to improve the performance of mainstream students in the final examination were made to the ECO1010S course. The decision to make these interventions was influenced by the success of the $\mathrm{ECO} 1010 \mathrm{H}$ cohort in previous years relative to the mainstream ECO1010S cohort. The focus was on improving the delivery of the lectures and the tutorials, and on the content of the tutorials and tests. It was fortunate that there was a more stable team of lecturers for the period 2003-2005. Lecturers were able to settle into their topics and they had the opportunity to develop their skills using the same material over the three-year period. Considerable effort was put into choosing, supporting and training tutors. The content of the tutorials was modelled on the ECO1010H tutorials and students were required to submit written answers to selected questions each week. These written answers counted $5 \%$ of their final course marks. Students were required to write three tests during the semester. These consisted of multiple-choice and essay/structured questions. As a result of these changes, the ECO1010S cohort was expected to be better prepared for the final examination, and particularly, to perform better in the essay/structured questions, conditional on a variety of explanatory variables, relative to the ECO1010H cohort. It was not expected that this cohort would match the performance of the $\mathrm{ECO} 1010 \mathrm{H}$ cohort on the essay/structured questions, conditional on the explanatory variables, as many of the interventions presumed to impact positively on students' performance in these questions remained the preserve of the ECO1010H course. In section 3 the empirical methodology used to identify the extent to which performance of academically disadvantaged students is enhanced by the academic development course $(\mathrm{ECO} 1010 \mathrm{H})$ is discussed. The methodology used to determine the extent to which the pedagogic interventions in the mainstream course (ECO1010S) enabled students to improve their performance relative to the ECO1010H cohort, in the second period (2003-2005), is outlined.

\section{EMPIRICAL METHODOLOGY}

\section{(a) Specification}

The performance of ECO1010H and ECO1010S students, who wrote the South African matriculation examination, ${ }^{9}$ is compared using the results of the final-year examination taken by both sets of students at the same sitting, for the years 1999 and 2001-2005.

Economics education is viewed as a production process whereby educational performance is a function of a variety of inputs (Edwards, 2000 and Smith and Edwards, 2007). This relationship can be represented as:

\section{OUTPUT $=$ F(D1010H, STUDENT, MATRCULATION PERFORMANCE, SCHOOL, COURSE, OTHER)}

where:

\footnotetext{
${ }^{9}$ More than $95 \%$ of the ECO1010H students are South African citizens who wrote that country's matriculation examination. To improve the match between the academic development and mainstream cohorts, international students and students who wrote other final examinations are excluded.
} 
OUTPUT is a measure of economic performance;

$\mathrm{D} 1010 \mathrm{H}$ is a dummy variable that equals 1 for ECO1010H students;

STUDENT includes variables measuring students' characteristics;

MATRICULATION PERFORMANCE includes variables measuring performance in school-leaving subjects;

SCHOOL includes variables for different types of schools

COURSE includes variables relating to university course characteristics; and

OTHER includes other relevant variables such as faculty registration and the Inverse Mills Ratio.

Following Smith and Edwards (2007) two measures of the stock of knowledge, as revealed in the examination results for multiple-choice and essay/structured questions, are used.

A dummy variable, $\mathrm{D} 1010 \mathrm{H}$, which equals 1 for the ECO1010H cohort, is used to assess the effectiveness of pedagogic interventions of an academic development type on students' performance in the first-year microeconomics course. A positive sign for the coefficient of $\mathrm{D} 1010 \mathrm{H}$ suggests that the academic development programme exerts a positive influence on students' performance relative to that of the other students. Of the ECO1010S cohort, $20 \%$ are doing first-year microeconomics for the first time. The majority of these students come from the engineering and science faculties and choose the course as one of their electives. A dummy variable, equal to 1, is included for those students who are taking first-year microeconomics for the first time. There is no a priori expectation as to the sign of this variable.

An interaction term, D1010H*PERIOD2, is also included to estimate the performance of the ECO1010H cohort relative to the ECO1010S cohort in the second period (2003-2005). The purpose of including this variable is to evaluate whether the innovations introduced in the second period do in fact improve the performance of ECO1010S students relative to ECO1010H students. A negative sign for the coefficient of this variable suggests that the performance of the ECO1010S students has improved in the second period relative to the performance of the ECO1010H cohort. However, should this be the case it is not possible to say which of the innovations is responsible for the improvement in the performance of the ECO1010S cohort.

The Heckman two-part procedure is used to account for the fact that not all students who started the course wrote the final examination. The main reason for their not writing is that they do not meet the requirements to do so. For example, students are generally required to write all the tests, hand in a certain number of tutorial assignments, and attend a certain number of tutorials. The exclusion of these students in the estimations may lead to sample-selection bias (Douglas and Sulock, 1995, and Parker, 2006). A relatively small proportion of students did not write the final examination: $4.9 \%$ of the ECO1010H cohort and 6.5\% of the ECO1010S cohort. These relatively small proportions suggest that the bias may not be large.

The first step of the Heckman procedure is to construct a probit estimation with a binary dependent variable which takes the value of 1 if the student wrote the final examination. The variables included in this estimation are age, schools, high-school economics, English as a home language, and whether the student was classified as "white" under the apartheid dispensation. All these variables are included in the 
estimations discussed above. In addition, one other variable is included; the student's score in the first test. Older students from private or model C schools, who were previously classified as "white", and who took economics at school, and have English as their home language are expected to experience less difficulty in adapting to the academic demands made of them at university, and, therefore, are more likely to write the final examination. Students who make a success of their first test are also deemed to be more likely to go on and complete the course and so qualify for the final examination. Using the results of the probit estimation, the econometrics software EVIEWS is used to calculate the Inverse Mills Ratio (IMR), which is then included in the ordinary least squares (OLS) estimations discussed below. The IMR is the variable which accounts for the bias that may result from the omission of the variables pertaining to those students who did not write the final examination.

To obtain the conditional impact of ECO1010H on examination performance, a number of variables that are thought to capture students' ability, knowledge and skills that facilitate economics understanding are treated as independent variables. These variables, selected on the basis of the international and South African literature ${ }^{10}$, include performance in school-leaving subjects, and course and student characteristics. Proxies for academic ability are important in explaining students' academic performance at university. Following Edwards (2000), Smith (2004), Van Walbeek (2004), and Smith and Edwards (2007), a modified version of the matriculation points score is used a measure of academic ability. ${ }^{11}$ Independent variables are included for English (HG) and mathematics (HG); therefore, the points allocated to these subjects are deducted. Two points are also deducted in respect of physical science (physics and chemistry (HG), as this subject is also treated as an independent variable. The coefficient of the adjusted matriculation score is expected to be positive for both the multiple-choice and structured/essay questions, and statistically significant. To allow for non-linearity the square of this variable is also included.

The school-leaving subjects identified above and economics (HG) are treated as independent variables. The results for English are mixed, and competence in mathematics is generally found to be strongly associated with performance in economics (Van Walbeek, 2004, Parker, 2006, and Smith and Edwards, 2007). Completion of physical science has been shown (Edwards, 2000, Smith, 2004, Van Walbeek, 2004, and Smith and Edwards, 2007) to be positively correlated with understanding economics in the South African literature, but has not been analysed in the international literature. The results of studies on the effect of high-school or prior economics courses on understanding economics at the tertiary level are mixed (Edwards, 2000, Parker, 2006, and Smith and Edwards, 2007). Dummy variables for each of these school-leaving subjects and dummy variables for various grade combinations are included. For English first language $(\mathrm{HG})$ the grade combinations are $(\mathrm{A}+\mathrm{B}+\mathrm{C}$ and $\mathrm{D}+\mathrm{E}+\mathrm{F})$ and for mathematics $(\mathrm{HG})(\mathrm{A}+\mathrm{B}+\mathrm{C}, \mathrm{D}$ and $\mathrm{E}+\mathrm{F})$. In general

\footnotetext{
${ }^{10}$ See Smith (2004) for a bibliography of the international literature, and Edwards (2000), Van Walbeek (2004), , Van der Merwe (2006), Parker (2006), Parker (2007), and Smith and Edwards (2007)

${ }^{11}$ The University of Cape Town allocates points to matriculation subjects as follows: Higher Grade $(H G): A=8, B=7, C=6, D=5, E=4, F=3$. Standard Grade $(S G)$ : Two points less for each grade.
} 
the coefficients of these variables are expected to be positive and statistically significant. However, as regards economics, the coefficient is expected to be negative as it is a subject generally chosen by students of lower academic ability (Smith and Edwards, 2007). For English and mathematics, progressively higher positive coefficients are expected as the grade improves.

There are strong grounds for expecting English (home language) to have a positive impact on performance in economics at universities where English is the medium of instruction (Edwards, 2000), but for other South African studies the results are mixed (Parker, 2006, and Smith and Edwards, 2007). A dummy variable is included that equals 1 if the student's home language is English. There is no a priori expectation as regards the sign of the coefficient for this variable.

Several studies report that females perform relatively well in essay questions, but relatively worse in multiple-choice questions (Edwards, 2000, Van Walbeek, 2004, and Smith and Edwards 2007). A dummy variable that equals 1 is included if the student is male. It is expected that the coefficient of this variable will be positive and statistically significant for the multiple-choice estimations.

Three further variables that were not included in Smith and Edwards's (2007) study are students' age at entry, school attended, and whether the student was previously classified as "white". It is suggested that there is a positive relationship between students' age and performance in economics; older students are more likely to have achieved the level of intellectual development necessary for mastering abstract processes (McConnell, 1980). However, the evidence regarding the significance of students' age is inconclusive (Park and Kerr, 1990, Tay, 1994, Van Walbeek, 2004, and Parker, 2006). Age is included as a continuous variable measured in years to the first decimal place. There is no a priori expectation as regards the sign of the coefficient for this variable.

Dummy variables, equal to 1 , are included for each of the following types of school: schools that in the apartheid era fell under the Department of Education and Training (DET), Houses of Representatives and Delegates (COHR), or catered for white people only (Model C); and private schools. ${ }^{12}$ It is expected that students from former DET and COHR schools will underperform students from private and Model C schools in the final examination although the supporting evidence is weak (Edwards, 2000, and Smith, 2004).

A dummy variable, equal to 1 , is included for students previously classified as "white" on the grounds that many advantages accrued to members of the white population under the apartheid system (Terreblanche, 2002). These advantages make it more likely that white children in South Africa have access to material resources that are unavailable to other children. They are more likely to have parents who themselves have a tertiary qualification. Also, they are more likely to come from family backgrounds where it is expected that they will go to university. It is expected that the coefficient of this variable will be positive and statistically significant.

\section{(b) Estimation issues and limitations}

In this study an attempt is made to deal with some of the sample selection issues identified in the Smith and Edwards' (2007) paper. Important variables such as

12 Other schools include technical, "cram" and correspondence colleges. 
students' effort, attitude and motivation are still omitted as it is difficult to find suitable proxies. The omission of these variables may result in biased estimates of the coefficients. In particular, if these omitted variables are positively correlated with the ECO1010H dummy, their effect on economic performance may be erroneously attributed to the $\mathrm{ECO} 1010 \mathrm{H}$ dummy variable. Also, it is possible, as regards the ECO1010S cohort, that its performance is negatively affected as the majority of students previously failed the first-semester course (ECO1010F). In this instance the relatively poor performance of the ECO1010S cohort may be the result of a lack of effort.

Another important consideration relates to possible sample-selection problems. The students in the ECO1010S cohort can only act as a control group if they are drawn from the same population as the ECO1010H cohort. ${ }^{13}$ Two sample-selection issues were identified in Smith and Edwards's (2007) paper. Firstly, not all students who start the course go on to write the final examination. The Heckman two-part procedure, described above, is used to account for this sample-selection problem.

The second issue is whether it can be assumed that ECO1010H and ECO1010S students are drawn from the same population measured across a broad range of characteristics. If not, the difference in the performance of the ECO1010H cohort might be due to their differing set of characteristics rather than the effectiveness of the teaching embodied in the ECO1010H course. To test for the extent of the similarity between the two cohorts, differences of means and proportions tests were conducted for each of the continuous and discrete variables. The results of this analysis are presented in Table 1.

It is clear that the two cohorts differ markedly from one another; in all cases the null hypothesis of equal means or proportions can be rejected. For example, the mean matriculation points score for the ECO1010S cohort is greater than the mean score for the $\mathrm{ECO} 1010 \mathrm{H}$ cohort, and is statistically significant at the $1 \%$ level. The proportion of students taking economics is greater for the ECO1010H cohort, and white students make up a larger proportion of the ECO1010S cohort. Importantly, the ECO1010S cohort shows a strong bias towards mathematics (HG), English first language (HG) and physical science $(\mathrm{HG})$. All these differences are statistically significant at the $1 \%$ level. Two adjustments were made to the samples in the Smith and Edwards's (2007) study to reduce the extent of the difference between the two cohorts. Firstly, students who obtained more than 36 , or less than 20 , matriculation points were excluded from the full samples in order to ensure that the two cohorts had a similar set of adjusted matriculation points scores. Secondly, students on the Commerce Academic Programme (44 in all) were also excluded on the basis that they were selected using a different set of criteria compared to other ECO1010H students. Although the differences between the ECO1010H and ECO1010S cohorts were reduced for the truncated samples they remained statistically significant at the $5 \%$ level for most of the variables. Also, the results of the estimations for the full and truncated samples were not particularly dissimilar from one another. Therefore these adjustments are not made in the present paper.

13 There is an extensive literature on sample-selection problems - this literature includes Park and Kerr (1990) and Raimondo, Esposito and Gershenberg (1990). 
However, as noted by Edwards (2000), the extent of the sample-selection problem may not be significant. There may be substantial random error associated with the main variable used to select students into $\mathrm{ECO} 1010 \mathrm{H}$, namely matriculation grades. The matriculation examinations differ, and the papers are graded by teams of examiners, across provinces. Therefore, it is probable that some students do the mainstream course when they should be registered for the academic development course in microeconomics and vice versa. Nonetheless, due consideration must still be given to potential sample-selection problems when interpreting the results.

Table 1. Control variables

\begin{tabular}{|c|c|c|c|}
\hline & $\begin{array}{c}\text { ECO } \\
1010 H\end{array}$ & $\begin{array}{l}\text { ECO } \\
1010 S\end{array}$ & Tests \\
\hline Personal characteristics & $\%$ share & $\%$ share & z-test \\
\hline African & 56.1 & 33.3 & 23.2 \\
\hline Indian & 7.7 & 11.0 & 13.8 \\
\hline Coloured & 25.8 & 16.8 & 18.0 \\
\hline White & 10.4 & 38.8 & 28.1 \\
\hline English home language (Enghome) & 42.8 & 64.9 & 22.7 \\
\hline Male & 49.7 & 53.1 & 8.8 \\
\hline & Mean & Mean & t-test \\
\hline Age & 18.4 & 18.8 & 5.9 \\
\hline School attended & & & \\
\hline Model C & 32.2 & 38.7 & 12.3 \\
\hline Private & 13.7 & 25.4 & 20.1 \\
\hline COHR & 16.9 & 9.7 & 19.8 \\
\hline DET & 23.5 & 9.4 & 25.9 \\
\hline Matriculation points & Mean & Mean & t-test \\
\hline $\begin{array}{l}\text { Mean matriculation points score } \\
\text { (Matpt) }\end{array}$ & 33.2 & 36.6 & 19.2 \\
\hline $\begin{array}{l}\text { Mean adjusted matriculation points } \\
\text { score (Adjmatpt) }\end{array}$ & 23.1 & 24.2 & 6.6 \\
\hline Matriculation subjects & \multicolumn{2}{|c|}{$\%$ share $\%$ share } & z-test \\
\hline $\begin{array}{l}\text { English first language (HG) } \\
\text { (Eng FL HG) }\end{array}$ & 66.5 & 86.4 & 26.2 \\
\hline Mathematics (HG) (Math HG) & $46.8 \%$ & $70.0 \%$ & 23.8 \\
\hline Physical science (HG) (PS HG) & $34.5 \%$ & $64.4 \%$ & 26.3 \\
\hline Economics & $23.7 \%$ & $10.7 \%$ & 24.2 \\
\hline \multicolumn{4}{|l|}{ Other } \\
\hline Commerce Faculty (Commerce) & $63.3 \%$ & $59.2 \%$ & 9.9 \\
\hline $\begin{array}{l}\text { ECO1010S students first registration } \\
\text { for ECO1010 (First time) }\end{array}$ & $0 \%$ & $19.8 \%$ & \\
\hline Observations & 886 & 1622 & \\
\hline
\end{tabular}

Note: The column titled "Tests" provides the t- and z-statistics for the tests of equality of means and proportions between ECO1010H and ECO1010S students.

\section{DATA AND RESULTS}

\section{(a) Analysis of data}

This section compares the final examination grades of the ECO1010H and ECO1010S students. The examination results for first-year microeconomics are presented in Table 2 .

The results show that the ECO1010H students outperformed the ECO1010S students by 4.2 percentage points in the structured/essay questions (statistically significant at the $1 \%$ level). However, the ECO1010S cohort had the greater success in the multiple- 
choice component of the final examination, also statistically significant at the $1 \%$ level. Overall, the ECO1010H cohort outperforms the ECO1010S cohort by 1.6 percentage points (statistically significant at the $1 \%$ level) in the final examination despite the fact that they exhibit a lower level of academic ability as measured by their performance in the matriculation examination (Table 1).

\section{Table 2. Examination results and t-statistics for the first-year microeconomics examination

Full sample
$1010 \mathrm{H} \quad 1010 \mathrm{~S}$ t-stat

Examination results

Structured/essay questions (SQ) \% $\quad 49.3 \quad 45.1 \quad 5.0^{*}$

Multiple-choice questions (MCQ) \% $\quad 54.5 \quad 57.8 \quad 7.0^{*}$

Examination (exam) \% $\quad 51.0 \quad 49.4 \quad 3.1^{*}$

Observations

$843 \quad 1516$

Note: * statistically significant at the $1 \%$ level.

\section{(b) Estimation results}

To evaluate the impact of the academic development course $(\mathrm{ECO} 1010 \mathrm{H})$ on performance in first-year microeconomics, the production function represented by equation (1) is estimated using OLS. An equation, Write, designed to identify the importance of selected variables in explaining whether students wrote the final examination or not, is estimated. The result of this specification is then used to calculate the IMR, which is then used as an additional explanatory variable in each of the following three estimations. Equation (1) is estimated using the multiple-choice question results in the final examination as the dependent variable and a selection of the variables in Table 1 as explanatory variables. The same relationship is estimated using the examination results for the structured/essay questions and for the examination results. Table 3 presents the results of these four estimations. Further, an extended specification is estimated that includes the interaction between $\mathrm{D} 1010 \mathrm{H}$ and a number of variables, and the square of the adjusted matriculation score. These estimations yield limited additional insight. Therefore, the relevant table is included in Appendix A. The probit estimation shows that the variables economics, test 1 mark, age and English home language are statistically significant in explaining whether the students wrote the final examination or not. For the latter two variables the coefficients have a negative sign. This suggests that older students, and students with English as their home language, are less likely to write the final examination. This result may warrant further investigation.

Turning to the multiple-choice question results, ECO1010H students outperform ECO1010S students by an average of 3.01 percentage points, conditional on the other explanatory variables (statistically significant at the 1\% level). This result contrasts with that of Smith and Edwards (2007), who found the advantage enjoyed by the ECO1010H cohort to be statistically insignificant. This suggests that the pedagogic interventions, designed primarily to improve the performance of ECO1010H students in the structured/essay questions, also improved their performance in the multiplechoice component of the final examination. For the structured/essay questions, the ECO1010H cohort outperforms the ECO1010S cohort by 10 percentage points on 
average (statistically significant at the $1 \%$ level). This finding mirrors that of Smith and Edwards (2007), who reported that ECO1010H students achieved an average of 15.6 to 15.9 percentage points more than the ECO1010S cohort, conditional on all the other variables. This robust result is consistent with the emphasis placed on English language and writing skills in the academic development course.

Table 3. Results of the first part of the Heckman two-part procedure, multiple-choice question, structured/essay question, and examination result estimations

\begin{tabular}{|c|c|c|c|c|}
\hline Variable & $\begin{array}{c}\text { Probit } \\
\text { Write }^{1}(1)\end{array}$ & $\begin{array}{c}\text { OLS } \\
\mathrm{MCQ}^{2}(2)\end{array}$ & $\begin{array}{c}\text { OLS } \\
\text { SQ }^{3} / \text { Essay (3) }\end{array}$ & $\begin{array}{c}\text { OLS } \\
\text { Exam (4) }\end{array}$ \\
\hline $\mathrm{C}$ & $3.48^{* * *}$ & $41.69 * * *$ & $29.92 * * *$ & $33.84 * * *$ \\
\hline D1010H & & $3.01 * * *$ & $10.00 * * *$ & $7.67^{* * *}$ \\
\hline D1010H*DPERIOD2 & & $-5.50 * * *$ & $-5.52 * * *$ & $-5.52^{* * *}$ \\
\hline Adjmatpt & & 0.69 & $1.09 * *$ & $0.96^{* *}$ \\
\hline D Economics & $0.27 * *$ & $-1.79 *$ & $-1.85^{*}$ & $-1.83^{* *}$ \\
\hline D Eng FL HG ABC & & 0.61 & 0.93 & 0.82 \\
\hline D Eng FL HG DEF & & -0.46 & 1.12 & 0.59 \\
\hline D Math HG ABC & & $6.10^{* * *}$ & $4.03^{* * *}$ & $4.72^{* * *}$ \\
\hline D Math HG D & & $3.92 * * *$ & $3.27^{* * *}$ & $3.49 * * *$ \\
\hline D Math HG EF & & $3.55^{* * *}$ & $2.39 * *$ & $2.78^{* * *}$ \\
\hline D PSHG & & $2.52^{* * *}$ & $1.41 *$ & $1.78^{* * *}$ \\
\hline Age & $-0.16^{* * *}$ & $1.65^{* * *}$ & $1.96^{* * *}$ & $1.85^{* * *}$ \\
\hline D English home & $-0.31 * *$ & -0.44 & 0.41 & 0.12 \\
\hline D Male & & $3.00^{* * *}$ & -0.25 & 0.83 \\
\hline D White & 0.09 & $3.43^{* * *}$ & $1.55^{*}$ & $2.17^{* * *}$ \\
\hline D COHR & 0.11 & $2.53^{*}$ & 0.58 & 1.23 \\
\hline D DET & 0.12 & 2.52 & $2.27 *$ & $2.35^{*}$ \\
\hline D Model C & $0.08^{*}$ & $3.37 * * *$ & 0.71 & $1.60^{* *}$ \\
\hline D Private & 0.04 & 1.41 & -1.09 & -0.26 \\
\hline D Commerce & & $2.78^{* * *}$ & $3.35^{* * *}$ & $3.16^{* * *}$ \\
\hline D First time & & 0.82 & 0.84 & 0.83 \\
\hline D PERIOD2 & -0.04 & -0.70 & $4.12^{* * *}$ & $2.51 * * *$ \\
\hline TEST 1 & $0.02^{* * *}$ & & & \\
\hline IMR & & $-139.75^{* * *}$ & $-161.16^{* * *}$ & $-154.02^{* * *}$ \\
\hline McFadden $\mathrm{R}^{2}$ & 0.130 & & & \\
\hline $\mathrm{R}^{2}$ & & 0.155 & 0.176 & 0.186 \\
\hline adj. $R^{2}$ & & 0.145 & 0.167 & 0.176 \\
\hline F-stat. & & $15.72^{* * *}$ & $18.31^{* * *}$ & $19.50^{* * *}$ \\
\hline Observations & 2508 & 2359 & 2359 & 2359 \\
\hline
\end{tabular}

\section{Notes:}

${ }^{1}$ Probit estimation for the first part of the Heckman two-part procedure.

${ }^{2}$ Multiple-choice questions

${ }^{3}$ Structured questions

$* * *, * *$ and $*$ represent statistical significance at $1 \%, 5 \%$ and $10 \%$, respectively.

The QML (Huber/White) standards errors and covariance used for "Write" estimation.

The White heteroskedasticity consistent standard errors and covariance test is used for the three OLS estimations.

The coefficients for the interaction term, D1010H*DPERIOD2, are -5.50 for the multiple-choice, and -5.52 for the structured/essay questions, respectively. Both results are statistically significant at the 1\% level, and suggest that the pedagogic interventions, designed to improve the performance of the ECO1010S cohort in the period 20032005 (period 2) relative to the ECO1010H cohort, were effective. The performance of the ECO1010S cohort improved by an average of 5.50 percentage points relative to the $\mathrm{ECO} 1010 \mathrm{H}$ cohort in the second period for both types of question. 
Looking at the other variables, the results are generally consistent with other studies in the field (Edwards, 2000, Smith, 2004, Van Walbeek, 2004, Parker, 2006, and Smith and Edwards, 2007). A background in mathematics (HG) improves performance in multiple-choice and structured/essay questions. For example, the average grade of students who achieved an A, B or C in mathematics (HG) (D Math HG ABC) was 3.55 to 6.10 percentage points higher than that of standard grade students for the multiplechoice questions, and 2.39 to 4.03 percentage points higher for the structured/essay questions.

These results indicate that a good grade in mathematics contributes positively towards achievement in first-year microeconomics. However, $53.2 \%$ of the ECO1010H cohort, and $30 \%$ of the ECO1010S cohort, did mathematics on the standard grade. Improving the content of and support for the mathematics component of microeconomics may yield returns in terms of improved student performance.

The coefficients for English first language (HG) grades A, B and C (D Eng FL HG $A B C$ ) are statistically insignificant. This is in contrast to the findings of Parker (2006) and Smith and Edwards (2007). This may suggest that the pedagogic interventions enabled students to overcome the disadvantages associated with having a relatively poor mark for English first language (HG) or with having taken English second language $(\mathrm{HG})$ in the matriculation examination. The coefficients for economics HG range from -1.79 to -1.85 , but are statistically significant at the $10 \%$ level, only. This result, supported by the findings of Smith and Edwards (2007), suggests that highschool courses in economics do not contribute towards improved performance in firstyear university-level microeconomics. These results contrast with those of Edwards (2000), who finds a positive coefficient, and Parker (2006), who reports negative coefficients for three of her five estimations.

The coefficient of the adjusted matriculation points score (Adjmatpt) is positive and statistically significant for the structured/essay estimation only. A 1.0 unit increase in the adjusted matriculation points score increases performance by 1.09 percentage points. Similar results are reported by Edwards (2000), Van Walbeek (2004) and Smith and Edwards (2007).

The results for the performance of male students relative to female students are largely consistent with international and South African studies for the multiple-choice component of the examination (Smith and Edwards, 2007). Male students achieved an average of 3.0 percentage points more than female students. The coefficient for English home language (Enghome) is statistically insignificant, which is contrary to the findings of Smith and Edwards (2007), who reported the coefficient of this variable to be negative and statistically significant. The coefficient for age is positive and statistically significant at the $1 \%$ level. For example, for every additional year of age, the performance of students in the structured/essay questions improves by 1.96 percentage points, on average. This finding may warrant further investigation. Students who would have been previously classified as "white" enjoy a premium of 1.55 to 3.43 percentage points, a result that is consistent with the priors. The type of school attended does not seem to be an important factor in determining performance, a finding that is contrary to the priors. That said, students who attended a Model $\mathrm{C}$ schools outperformed their peers by 3.37 percentage points in the multiple-choice questions; this finding is statistically significant at the $1 \%$ level. Students who are registered in the commerce faculty (Commerce) outperformed their peers by 2.78 to 3.35 percentage points 
(statistically significant at the 1\% level). Smith and Edwards (2007) report similar statistically significant coefficients. The coefficients for students who did microeconomics for the first time in ECO1010S (First time) are statistically insignificant. This suggests that students repeating the microeconomics course enjoyed no advantage over their peers who were doing it for the first time. This result may also suggest that the performance of those students who were repeating the course was not necessarily negatively affected by their lack of effort.

Finally, the coefficient for the inverse Mills ratio (IMR) is negative and statistically significant for both the multiple-choice and structured/essay question estimations. This suggests that excluding those students who did not write the final examination from the estimations leads to a biased set of results. For example, the negative coefficient for English home language reported by Smith and Edwards (2007) is not found in this study, as this variable is statistically significant in explaining whether students wrote the final examination or not.

The estimations including interaction terms (see Appendix A) are now considered. The estimation for the multiple-choice questions yields two statistically significant results for ECO1010H. Male and white students who were members of the ECO1010H cohort outperformed their peers in the ECO1010S cohort. This suggests that males and white students gained some additional advantage from the ECO1010H course that was not available to ECO1010S students with the same characteristics. These two findings may warrant further investigation. Aside from these two variables the performance of ECO1010H students in multiple-choice questions seems to be equivalent to other students conditional on the other variables included in the estimation. The structured/essay questions estimation suggests that ECO1010H students who have English as their home language underperform their ECO1010S counterparts by an average of 7.10 percentage points. This result may also warrant further investigation.

\section{(c) Pass rates}

The purpose of the examination estimation (column 4) is to identify the premium associated with the ECO1010H course. ECO1010H students outperform their peers in ECO1010S by an average of 7.67 percentage points. Using this information, it is possible to determine the effect of this premium on the pass rate attained by the ECO1010H cohorts over the six-year period. The results are presented in Table 4.

\begin{tabular}{|c|c|c|}
\hline & Total (1) & Percentage (2) \\
\hline Number of students & 843 & 100 \\
\hline $\begin{array}{l}\text { Pass (premium of } 7.67 \\
\text { percentage points) }\end{array}$ & 476 & 56.5 \\
\hline Pass (no premium) & 316 & 37.5 \\
\hline
\end{tabular}

The average pass rate for the six-year period is $56.5 \%$. However, if these same students had attended the ECO1010S course, they would not have enjoyed the premium of 7.67 percentage points. The pass rate for the 843 students who wrote the final examination would have fallen to $37.5 \%$. In other words, 160 students can be said to have passed the examination they otherwise would not have passed. This represents $19 \%$ of the cohort. 
Overall, the results provide strong evidence that ECO1010H contributes positively towards performance in first-year microeconomics, particularly in the structured/essay questions. This suggests that the interventions incorporated in the ECO1010H course, to improve students' learning, English language, writing and quantitative skills, were partly successful in enabling students to overcome some of their educational disadvantages. Further, the improved performance of the ECO1010S cohort in the second period, relative to the ECO1010H cohort, suggests that a selection of these selfsame interventions is also effective in improving the performance of students completing a mainstream course in first-year microeconomics.

\section{CONCLUSION}

In this paper the effectiveness of pedagogic interventions in first-year academic development and mainstream microeconomics courses on students' economics understanding in first-year microeconomics is investigated. Three issues are addressed that have not been considered in previous studies. Firstly, the effect of pedagogic interventions of an academic development type on the performance of mainstream students relative to the academic development cohort is evaluated. Secondly, the Heckman two-part procedure is used to deal with some aspects of the sample-selection problem. Thirdly, data for six years is pooled resulting in a sample size some five times larger than the average of the sample sizes reported in the studies cited in this paper.

To the extent that the ECO1010H cohort outperformed the control group it is possible to draw the following conclusions, leaving aside the problem of sample-selection bias. The results suggest that the ECO1010H course has a positive impact on students' performance in the multiple-choice and structured/essay questions, relative to the control group for the six-year period. The positive impact is particularly marked for the essay/structured questions. The results also suggest that these interventions have had a positive impact on the performance of mainstream students completing the same course and writing the same final examination. These two findings lend support to the view that the nature of the pedagogic interventions are such that they are effective in the longer term. Finally, the results suggest that the pass rate for the ECO1010H cohort in the final examination is 19 percentage points greater than it would have been if the academic development students had attended the mainstream course in first-year microeconomics.

The key variables that may explain the relative success of the pedagogic interventions in the academic development course include the tutorials in economics, and language and communication, essay writing, the module designed to develop students' quantitative and graphical skills, and the smaller class size. The focus on improving students' writing and English language skills may go some way in explaining their strong performance in the structured/essay questions relative to the mainstream cohort. Improved performance by the mainstream cohort may be due to the more intensive tutorial system that focussed on developing students writing skills, and the more stable team of lecturers.

The robust and positive nature of the relationship between the $\mathrm{ECO} 1010 \mathrm{H}$ course and students' examination performance, and between the pedagogic interventions and ECO1010S students' performance in the second period, suggest that the aims of the 
pedagogic interventions - to improve students' learning, English language, writing and quantitative skills - are partly met.

\section{APPENDIX A}

\begin{tabular}{|c|c|c|c|}
\hline Variable & $\begin{array}{c}\text { OLS } \\
\text { MCQ }^{1}\end{array}$ & $\begin{array}{l}\text { OLS } \\
\mathrm{SQ}^{2}\end{array}$ & $\begin{array}{c}\text { OLS } \\
\text { Examination }\end{array}$ \\
\hline $\mathrm{C}$ & $46.14 * * *$ & $32.88^{* * *}$ & $37.30 * * *$ \\
\hline D1010H & $-10.65^{*}$ & 4.96 & -0.24 \\
\hline D1010H*DPERIOD2 & $-7.58^{* * *}$ & $-7.44 * * *$ & $-7.49 * * *$ \\
\hline Adjmatpt & 0.80 & 0.72 & 0.75 \\
\hline Adjmatpt $*$ Adjmatpt & -0.00 & -0.01 & -0.00 \\
\hline D1010H* Adjmatpt & 0.39 & $0.38 *$ & $0.38^{* *}$ \\
\hline D Economics & -0.85 & -1.78 & -1.47 \\
\hline D1010H*D Economics & -2.37 & -0.43 & -1.08 \\
\hline D Eng FL HG & -0.44 & $2.64 *$ & 1.61 \\
\hline D1010H*Eng FL HG & 0.82 & -2.79 & -1.59 \\
\hline D Math HG & $3.33^{* * *}$ & $2.88^{* * *}$ & $3.03 * * *$ \\
\hline D1010H* Math HG & 2.49 & 1.44 & 1.79 \\
\hline D PS HG & $3.14 * * *$ & 0.90 & $1.65^{* *}$ \\
\hline D1010H*PS HG & -0.60 & 1.50 & 0.80 \\
\hline Age & $1.56^{* * *}$ & $1.96^{* * *}$ & $1.83^{* * *}$ \\
\hline D Enghome & 0.98 & $3.24 * * *$ & $2.49 * * *$ \\
\hline D1010H*D Enghome & -2.60 & $-7.10^{* * *}$ & $-5.60 * * *$ \\
\hline D Male & 0.83 & -0.40 & 0.01 \\
\hline D1010H*D Male & $4.76^{* * *}$ & -0.17 & 1.47 \\
\hline D White & $2.75^{* * *}$ & 0.84 & $1.48^{*}$ \\
\hline D1010H*D White & $6.57^{* * *}$ & 2.42 & $3.80 *$ \\
\hline COHR & 2.59 & 0.50 & 1.20 \\
\hline D1010H*COHR & -0.17 & 1.13 & 0.70 \\
\hline D DET & 3.43 & $3.64 * *$ & $3.57^{* *}$ \\
\hline D1010H*D DET & -1.46 & -2.69 & -2.28 \\
\hline D Model C & $3.03^{* *}$ & 0.63 & 1.43 \\
\hline D1010H*D Model C & 0.63 & 0.22 & 0.36 \\
\hline D Private & $2.19 *$ & -1.53 & -0.29 \\
\hline D1010H*D Private & -1.51 & 1.72 & 0.64 \\
\hline D Commerce & $1.89 * *$ & $2.41 * * *$ & $2.23^{* * *}$ \\
\hline D1010H*D Commerce ${ }^{1}$ & $3.49 *$ & 1.42 & 2.11 \\
\hline First time & 1.33 & 0.89 & 1.04 \\
\hline D PERIOD2 & -0.13 & $4.55^{* * *}$ & $2.99 * * *$ \\
\hline MILLS & $-144.07 * * *$ & $-158.54 * * *$ & $-153.71 * * *$ \\
\hline $\mathrm{R}^{2}$ & 0.166 & 0.191 & 0.197 \\
\hline Adj. $\mathrm{R}^{2}$ & 0.152 & 0.177 & 0.184 \\
\hline F-stat. & $11.84 * * *$ & $13.98^{* * *}$ & $14.57^{* * *}$ \\
\hline Observations & 2508 & 2508 & 2508 \\
\hline
\end{tabular}

Notes:

${ }^{1}$ Multiple-choice questions

2 Structured questions

$* * *, * *$ and $*$ represent statistical significance at $1 \%, 5 \%$ and $10 \%$, respectively.

The White heteroskedasticity consistent standard errors and covariance test is used for all the OLS estimations.

\section{REFERENCES}

ALSTON, R. and NOWELL, C. (2007). I thought I got an A! Overconfidence across the economics curriculum. Journal of Economic Education, 38 (2): 131-142.

ANSTINE, J. and SKIDMORE, M. (2005). A small sample study of traditional and on-line courses 
with sample selection adjustment. Journal of Economic Education, 36 (2): 107-128.

ARIAS, J.J. and WALKER, D.M. (2004). Additional evidence on the relationship between class size and student performance. Journal of Economic Education, 35 (4): 311-329.

ASHWORTH, J. and EVANS, J.L. (2001). Modelling student subject choice at secondary and tertiary level: A cross-section study. Journal of Economic Education, 32 (4): 311-320.

BETTINGER, E.P. and LONG, T.L. (2005). Addressing the needs of under-prepared students in higher education: Does college remediation work? National Bureau of Economic Research, Working Paper 11325. BOSSHARDT, W. (2004). Student drops and failure in principles courses. Journal of Economic Education, 35 (2): 111-128.

BOYLAN, H.R. and SAXON, D.P. (1999). Outcomes of remediation. Retrieved 25 May, 2008 from http:/www.ncde.appstate.edu/reserve_reading/Outcome_of_Remediation.htm

BROTHEN, T. and WAMBACH, C.A. (2004). Refocusing developmental education. Journal of Developmental Education, 28 (2): 18-33).

CHIZMAR, J.F. (2000). A discrete-time hazard analysis of the role of gender in persistence in the economics major. Journal of Economic Education, 31 (2): 107-118.

CURTIS, P.J.D. and DE VILLIERS, J. (1992). The academic effectiveness of a bridging year for commerce undergraduates. Development Southern Africa, 9 (November): 457-470.

DE VILLIERS, J. and RWIGEMA, H. (1998). The effect of a bridging year on the graduation success of educationally disadvantaged commerce students. South African Journal of Higher Education, 12 (1): 103-108.

DOUGLAS, S. and SULOCK, J. (1995). Estimating production functions with correction for drops. Journal of Economic Education, 26 (2): 101-112.

EDWARDS, L. (2000). An econometric evaluation of academic development programmes in economics. South African Journal of Economics, 68 (3): 455-483.

GROVE, W.A., WASSERMAN, T. and GRODNER, A. (2006). Choosing a proxy for academic aptitude. Journal of Economic Education, 37 (2): 131-147.

HECKMAN, J.T. 1979, Sample selection bias as a specification error. Econometrica, 47, January: 153-161.

HESKETH, J., MBALI, C. and MKHIZE, N. (1994). What makes them fail? An investigation into

Economics 1A. Proceedings of the 9th conference of the South African Association for Academic Development, University of Natal, Durban.

KROHN, G.A. and O'CONNOR, C.M. (2005). Student effort and performance over the semester. Journal of Economic Education, 36 (1): 3-28.

MARBURGER, D.R. (2001). Absenteeism and undergraduate exam performance. Journal of Economic Education, 31 (2): 99-109.

- (2006). Does mandatory attendance improve student performance? Journal of Economic Education, 37 (2): $148-155$.

MCCONNELL, C. 1980, Economics 101: Where do we stand? Journal of Economic Education, 12 (1): 15-22. MACDONALD, R.B. and O'HEAR, M.F. (1996). A critical review of research in developmental education: Part 2. Journal of Developmental Education, 19 (3): 8-14.

MCPHERSON, M.A. (2006). Determinants of how students evaluate teachers. Journal of Economic Education, 37 (1): 13-20.

O'HEAR, M.F. and MACDONALD, R.B. (1995). A critical review of research in developmental education: Part 1. Journal of Developmental Education, 19 (2): 2-6,

PARK, K.H. and KERR, P. (1990). Determinants of academic performance: A multinomial approach. Journal of Economic Education, 21 (2): 101-111.

PARKER, K. (2006). The effect of student characteristics on achievement in introductory microeconomics in South Africa. South African Journal of Economics, 74 (1): 137-149.

- (2007). Correcting for sampling bias in education production functions. South African Journal of Economics, 75 (1): 118-124.

RAIMONDO, H.J., ESPOSITO, L. and GERSHENBERG, I. (1990). Introductory class size and student performance in intermediate theory courses. Journal of Economic Education, 21 (4): 369-381.

RAMIREZ, G.M. (1997). Supplemental instruction: The longterm impact. Journal of Developmental Education, 21 (1): 2-9).

SMITH L.C. (2004). A multivariate evaluation of mainstream and academic development courses in firstyear microeconomics at the University of Cape Town: A comparative study. Unpublished Masters dissertation, School of Economics, University of Cape Town.

and EDWARDS, L.E. (2007). A multivariate evaluation of mainstream and academic development courses in first-year microeconomics. South African Journal of Economics, 75 (1): 99-117. 
SOWELL, E. (2004). Grade dropping: An empirical analysis. Journal of Economic Education, 35 (1): 24-34. STANCA, L. (2006). The effects of attendance on academic performance: Panel data evidence for introductory microeconomics. Journal of Economic Education, 37 (3): 251-266.

SWOPE, K.J. and SCHMITT, P.M. (2006). The performance of economics graduates over the entire curriculum: The determinants of success. Journal of Economic Education, 37 (4): 387-394.

TAY, R. (1994). Students' performance in economics: Does the norm hold across cultural and institutional settings? Journal of Economic Education, 25 (4): 291-301.

TERREBLANCHE, S. (2002). A History of Inequality in South Africa 1652-2002. University of Natal Press, Scottsville and KMM Review Publishing, Sandton.

VAN DER MERWE, A. (2006). Identifying some constraints in first year economics teaching at a typical South African university of technology. South African Journal of Economics, 74 (1): 150-159.

VAN WALBEEK, C. (2004). Does lecture attendance matter? Some observations from a first-year economics course at the University of Cape Town. South African Journal of Economics, 72 (3): 11-32.

VOLBRECHT, T. (1999). Mainstreaming academic development at the University of the Western Cape: A case of "Mission Impossible" or Just "Messiness Inevitable"? Academic Development, 3 (1).

WALKER, M. and BADSHA, N. (1993). Academic development and the challenge of curriculum change at the University of the Western Cape: An overview. AD Dialogues, 1: 1-14.

WEISMANN, J., BULAKOWSKI, C. and JUMISKO, M.K. (1997). Using research to evaluate developmental education programs and policies. New Directions for Community Colleges, 100: 73-80. ZIEGERT, A.L. (2000). The role of personality, temperament and student learning in principles of economics: Further evidence. Journal of Economic Education, 31 (4): 307-322. 